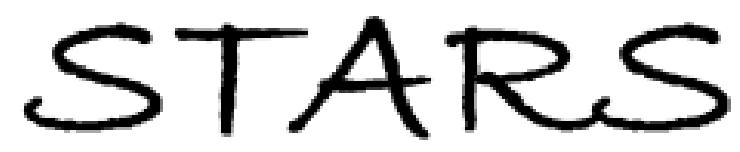

University of Central Florida

STARS

$1-1-2006$

\title{
Neutron diffraction investigation of hysteresis reduction and increase in linearity in the stress-strain response of superelastic $\mathrm{NiTi}$
}

\author{
C. R. Rathod \\ University of Central Florida \\ B. Clausen \\ M. A. M. Bourke \\ R. Vaidyanathan \\ University of Central Florida
}

Find similar works at: https://stars.library.ucf.edu/facultybib2000

University of Central Florida Libraries http://library.ucf.edu

This Article is brought to you for free and open access by the Faculty Bibliography at STARS. It has been accepted for inclusion in Faculty Bibliography 2000s by an authorized administrator of STARS. For more information, please contactSTARS@ucf.edu.

\section{Recommended Citation}

Rathod, C. R.; Clausen, B.; Bourke, M. A. M.; and Vaidyanathan, R., "Neutron diffraction investigation of hysteresis reduction and increase in linearity in the stress-strain response of superelastic NiTi" (2006). Faculty Bibliography 2000s. 6492.

https://stars.library.ucf.edu/facultybib2000/6492

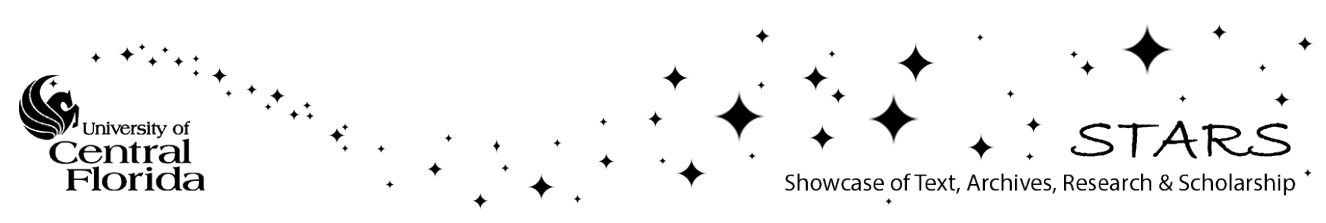




\section{Neutron diffraction investigation of hysteresis reduction and increase in linearity in the stress-strain response of superelastic NiTi}

Cite as: Appl. Phys. Lett. 88, 201919 (2006); https://doi.org/10.1063/1.2204650

Submitted: 11 November 2005 . Accepted: 05 April 2006. Published Online: 18 May 2006

C. R. Rathod, B. Clausen, M. A. M. Bourke, and R. Vaidyanathan

\section{ARTICLES YOU MAY BE INTERESTED IN}

Stress hysteresis and temperature dependence of phase transition stress in nanostructured NiTi-Effects of grain size

Applied Physics Letters 103, 021902 (2013); https://doi.org/10.1063/1.4812643

Measurement of the lattice plane strain and phase fraction evolution during heating and cooling in shape memory NiTi

Applied Physics Letters 95, 141906 (2009); https://doi.org/10.1063/1.3245308

Analysis of neutron diffraction spectra acquired in situ during stress-induced transformations in superelastic NiTi

Journal of Applied Physics 86, 3020 (1999); https://doi.org/10.1063/1.371163
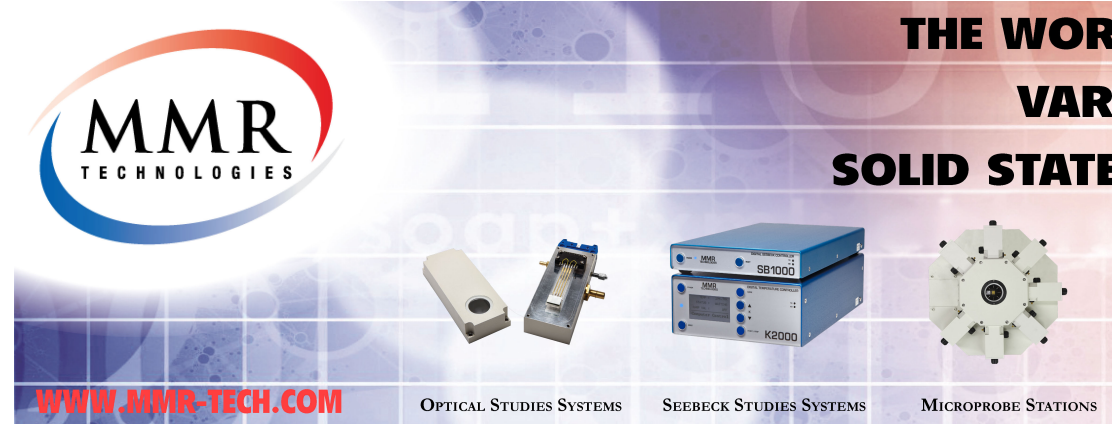

VARIABLE TEMPERATURE

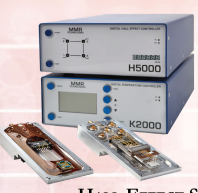

Hall Effect Study Systems and Magnets 


\title{
Neutron diffraction investigation of hysteresis reduction and increase in linearity in the stress-strain response of superelastic NiTi
}

\author{
C. R. Rathod \\ Advanced Materials Processing and Analysis Center (AMPAC) and Mechanical, Materials, and Aerospace \\ Engineering, University of Central Florida, Orlando, Florida 32816 \\ B. Clausen and M. A. M. Bourke \\ LANSCE/MST, Los Alamos National Laboratory, Los Alamos, New Mexico 87455 \\ R. Vaidyanathan ${ }^{\text {a) }}$ \\ Advanced Materials Processing and Analysis Center (AMPAC) and Mechanical, Materials, and Aerospace \\ Engineering, University of Central Florida, Orlando, Florida 32816
}

(Received 11 November 2005; accepted 5 April 2006; published online 18 May 2006)

In situ neutron diffraction measurements during loading have been performed on plastically deformed superelastic NiTi samples. The measurements observed retained B19' phase in the unloaded state as a result of the plastic deformation in otherwise completely B2 phase samples. A reversible stress-induced B2-B19' transformation on application and removal of stress occurred in the presence of this retained $\mathrm{B} 19^{\prime}$ phase. The amount and orientation of this retained $\mathrm{B} 19^{\prime}$ phase changed with cycling. Such direct atomic scale observations in the bulk are used here for the first time to qualitatively elucidate the macroscopic stress-strain response in plastically deformed superelastic NiTi. (C) 2006 American Institute of Physics. [DOI: 10.1063/1.2204650]

The superelastic effect in near equiatomic NiTi is associated with a thermoelastic stress induced martensitic phase transformation, generating strains typically around $8 \%$, and a reverse transformation on unloading, with concomitant recovery of the strains. This reversible phase transformation occurs between a cubic B2, austenite phase and a monoclinic B19', martensite phase. Thermodynamically, the transformation is controlled by a balance of chemical free energy, elastic strain energy, the energy associated with frictional resistance to interfacial motion, and similar dissipative processes. ${ }^{1,2}$ The energy dissipation, e.g., frictional resistance to interfacial motion, requires additional stress for the forward transformation while lowering the stress for the reverse transformation. This hysteresis introduces a loop in the macroscopic stress-strain response between load and unload.

Given the substantial recoverable strain, superelastic NiTi can store more energy in applications such as springs than nonsuperelastic materials. However, the nonlinear stress-strain response and hysteresis impede mechanical design. One way to reduce the hysteresis and increase linearity in the stress-strain response is to cold work or plastically deform the material. Previous studies ${ }^{3-7}$ on NiTi have documented the effect of plastic deformation on the stress-strain response. This includes the phenomenon of linear superelasticity for high percentages (usually above 30\%) of plastic deformation. ${ }^{4}$ Theories ${ }^{8-11}$ have been proposed to explain these changes, but no experimental studies have simultaneously examined the micromechanical and microstructural changes associated with the reduction in hysteresis and increase in linearity in the mechanical response of bulk superelastic NiTi. Furthermore, a majority of the studies have examined heavily (above 30\%) plastically deformed NiTi.

In situ neutron diffraction studies during loading can be used to study the texture, strain, and phase fraction evolution

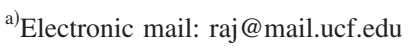

in active materials ${ }^{12}$ such as NiTi. ${ }^{13-15}$ When compared to (low energy) $\mathrm{x}$-ray, the increased penetration of neutrons is more representative of bulk polycrystal behavior and is typically free of surface effects. By recourse to in situ neutron diffraction experiments during loading, this work provides for the first time a connection between atomic-scale phenomena and macroscopic changes in superelastic NiTi with increasing plastic deformation, namely, hysteresis reduction and increase in linearity in the stress-strain response. The neutron diffraction measurements also assess the effect of cyclic loading on such plastically deformed samples.

Commercially available NiTi (55.94 wt \% Ni) bars were obtained from Special Metals Corporation, New Hartford, NY. These bars were cold drawn from cast ingots, produced by vacuum induction melting followed by vacuum arc remelting. The bars were subsequently annealed at $550{ }^{\circ} \mathrm{C}$ for $20 \mathrm{~min}$ and quenched in ice water. Cylindrical compression NiTi specimens (10 $\mathrm{mm}$ in diameter and $24 \mathrm{~mm}$ in length) were cut from the bars by electrical discharge machining, solutionized at $1000{ }^{\circ} \mathrm{C}$ for $1 \mathrm{~h}$ in argon and oil quenched to room temperature. A final anneal was applied at $400{ }^{\circ} \mathrm{C}$ in air for $1 \mathrm{~h}$ followed by a ice-water quench. The austenite finish, austenite start, martensite start, and martensite finish temperatures were determined by differential scanning calorimetry to be $9.9,-0.5,-30.4$, and $-59.7^{\circ} \mathrm{C}$, respectively. Two specimens were plastically compressed by $8 \%$ and $11 \%$, respectively, and remachined to cylindrical specimens $8 \mathrm{~mm}$ in diameter and $20 \mathrm{~mm}$ in length. The amount of plastic deformation was selected so as to monitor phenomenology the responsible for the progression of a nonlinear, hysteretic, load-unload response to one with increased linearity and reduced hysteresis, rather than to examine heavily plastically deformed samples (as in majority of the previously mentioned investigations). The two $8 \%$ and $11 \%$ plastically deformed samples and a sample with no plastic deformation were deformed up to $1400 \mathrm{MPa}$ (load-unload cycle) six, three, and eight times, respectively. The purpose of these 


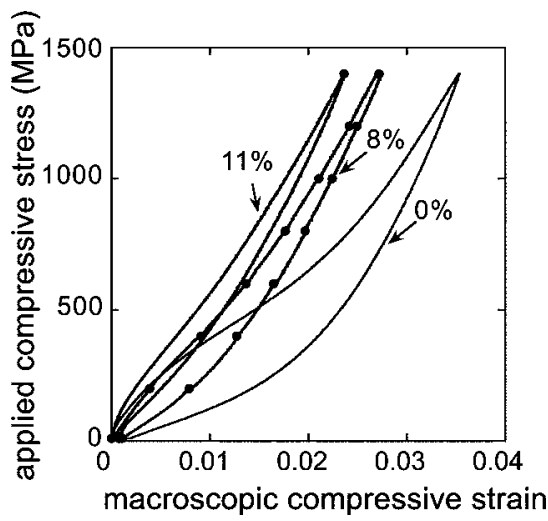

FIG. 1. Applied compressive stress vs macroscopic compressive strain measured by extensometry for undeformed, $8 \%$, and $11 \%$ plastically deformed NiTi. The symbols $(\bullet)$ represent the stresses at which neutron diffraction spectra were recorded.

mechanical cycles was to homogenize and remove any instabilities associated with the transformation while ensuring that the nonrecoverable strain was minimal. ${ }^{16}$

In situ neutron diffraction measurements during compressive loading were performed using the Spectrometer for Materials Research at Temperature and Stress (SMARTS) at the Los Alamos Neutron Science Center at Los Alamos National Laboratory, Los Alamos, NM. An extensometer recorded macroscopic strain during the experiments. The load was ramped in stroke control at $0.01 \mathrm{~mm} / \mathrm{min}$ and kept constant during hold periods when diffraction spectra were collected. Hold periods were approximately $40 \mathrm{~min}$, depending on the beam intensity (average of $100 \mu \mathrm{Ah}$ ). During the experiments, the incident neutrons formed a $45^{\circ}$ angle with the loading axis, and detectors recorded the diffraction pattern with scattering vectors parallel and perpendicular to the loading axis.

Figure 1 is the macroscopic stress-strain response from extensometry of the samples with $0 \%, 8 \%$, and $11 \%$ residual plastic deformations. The solid symbols indicate the stresses at which neutron diffraction spectra were obtained. Previously, work has characterized undeformed superelastic NiTi using in situ neutron diffraction during loading ${ }^{17,18}$ and hence only one measurement was made in the unloaded condition in the undeformed sample. For the sample previously deformed to $8 \%$ plastic strain, neutron spectra corresponding to 14 stresses up to $1400 \mathrm{MPa}$ were acquired. For the sample with $11 \%$ residual plastic strain, neutron spectra were acquired in the unloaded condition and at $1400 \mathrm{MPa}$. Figure 1 shows that with increasing plastic deformation the hysteresis and maximum recoverable strain decrease while linearity in the stress-strain curve increases.

Figure 2 compares spectra from the three samples $(0 \%$, $8 \%$, and $11 \%$ prior deformation) in the unloaded state. The spectra are normalized by the incident beam spectrum. As expected from the composition and the transformation temperatures reported, the NiTi sample with no prior plastic deformation is fully austenitic in the unloaded condition. This contrasts with the $8 \%$ and $11 \%$ deformed samples which both show the presence of martensite. Thus the residual plastic strain, which is expected to generate various crystallographic defects such as dislocations, among others, and their resulting internal stress field result in the stabilization of martensite in the unloaded condition.

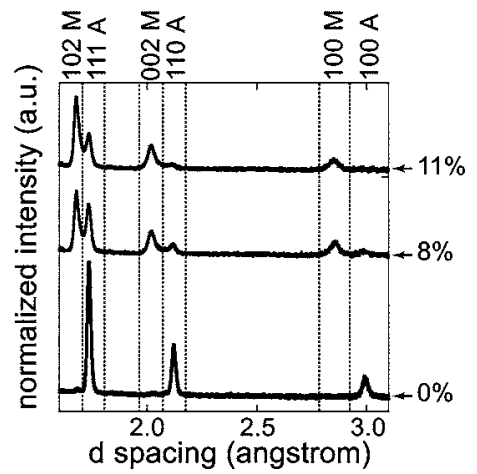

FIG. 2. Section of normalized diffraction spectra for $0 \%, 8 \%$, and $11 \%$ plastically deformed NiTi at no load. The scattering vector is parallel to the prior deformation. The austenite (A) and martensite (M) peaks are identified.

Figure 3 shows a section of spectra from the sample with $8 \%$ prior plastic strain during loading and unloading. This figure illustrates the reversibility of the stress-induced transformation in the presence of the stabilized martensite. Upon loading, the shift to smaller $d$ spacings results from the elastic compressive strain, while the decrease in intensity of the 111 austenite peak and concomitant increase in the intensity of 102 martensite peak are due to the forward phase transformation. On unloading, the reverse holds true.

Figure 4 is presented to illustrate the effect of cycling. It includes normalized spectra from the first and sixth cycles of the sample with $8 \%$ residual plastic strain in the unloaded condition. Again, here spectra are normalized by the incident spectrum. The inset shows the corresponding macroscopic stress-strain curve from extensometry. The nonrecoverable strain following a load-unload cycle is minimal in the sixth cycle when compared to the first cycle. The ratio of the intensity of the 100 martensite peak at $2.86 \AA$ to that of the 100 austenite peak at $2.98 \AA$ increases from 1.11 after the first cycle to 1.48 after the sixth cycle. Qualitatively, this is consistent with either stabilization of additional martensite or texture evolution in the martensite. Previous work has shown evidence of both phenomena occurring for the case of NiTi. ${ }^{19}$

The preceding presentation has set the stage for a comparison of the macroscopic behavior of NiTi subjected to residual plastic strains (Fig. 1) with atomic scale phenomena from neutron diffraction spectra (Figs. 2-4). The martensite that is formed due to the application of stress is able to accommodate the mismatch with martensite that is stabilized from stresses associated with the residual plastic strain. The

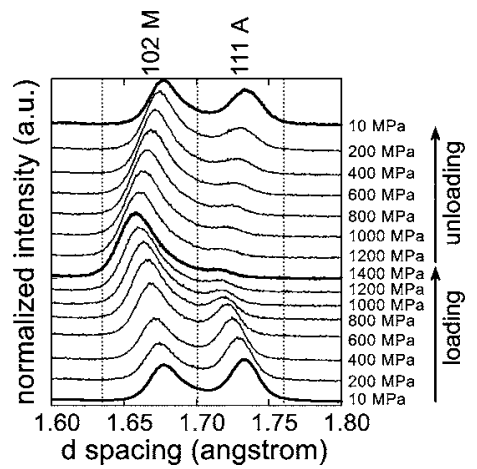

FIG. 3. Section of diffraction spectra for $8 \%$ plastically deformed NiTi at different applied stresses. The spectra are normalized and displaced vertically for clarity. The scattering vector is parallel to the loading direction. The austenite (A) and martensite (M) peaks are identified. 


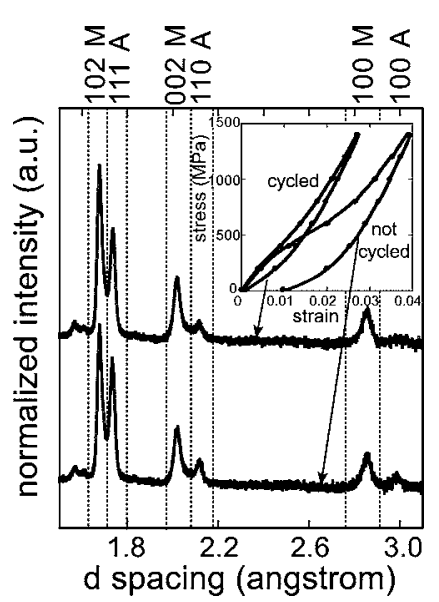

FIG. 4. Section of diffraction spectra from unloaded $8 \%$ plastically deformed NiTi without and with cycling (six $1400 \mathrm{MPa}$ load-unload cycles). The scattering vector is parallel to the loading direction. Inset shows the respective macroscopic stress-strain curves from $8 \%$ plastically deformed NiTi with and without cycling. The austenite (A) and martensite (M) peaks are identified.

mismatch is fully accommodated elastically following cycling as seen in the closed nature of the stress-strain curve or the absence of any nonrecoverable strain upon loading. Prior to this elastic accommodation, the initial cycles (six in the case of the sample with $8 \%$ residual plastic strain) involve inelastic accommodation. The inelastic accommodation is associated with phase fraction and texture evolution (through twinning) in the martensite phase. Figure 3 shows the reversibility of the stress-induced transformation in the bulk enabling the phase transformation to still be considered a reversible thermoelastic one, thereby subject to classic thermodynamic theory. ${ }^{1,2}$ Application of such a theory associates the increased stored elastic strain energy with increase in linearity in the stress-strain response. The increased defect density and accompanying stress field as a result of the plastic deformation can be expected to cause such a change in the stored elastic strain energy. The decreased hysteresis would then be associated with decreased frictional resistance to interfacial motion and decreased stored elastic strain energy dissipation. Again, the increased defect density and accompanying stress field can be expected to favorably select martensite variants or result in variant coalescence that reduces the overall energy dissipation. The stabilized martensite (and its ability to twin) may also be a contributing factor. The overall reversible strain scales with the volume fraction of transformable martensite, which was observed to decrease with residual plastic deformation from the neutron diffraction observations.

The present work demonstrates a qualitative connection between the microscopic and macroscopic changes associated with the reduction in hysteresis and increase in linearity as a result of residual plastic deformation in the mechanical response of bulk superelastic NiTi. It sets the stage for a quantitative investigation (using Rietveld analyses of complete diffraction spectra) that incorporates differential scanning calorimetry measurements of enthalpy changes to assess changes in the elastic strain energy.

The Los Alamos Neutron Science Center is a national user facility funded by the United States Department of Energy, Office of Basic Energy Sciences, under Contract No. W-7405-ENG-36. One of the authors (R.V.) gratefully acknowledges financial support from NASA (NAG3-2751) and NSF CAREER (DMR-0239512).

${ }^{1}$ R. J. Salzbrenner and M. Cohen, Acta Metall. 27, 739 (1979).

${ }^{2}$ G. B. Olson and M. Cohen, Scr. Metall. 9, 1247 (1975).

${ }^{3}$ R. F. Hamilton, H. Sehitoglu, Y. Chumlyakov, and H. J. Maier, Acta Mater. 52, 3383 (2004).

${ }^{4}$ G. R. Zadno and T. W. Duerig, in Engineering Aspects of Shape Memory Alloys, edited by C. M. Wayman and T. W. Duerig (ButterworthHeinmann, London, 1990), pp. 414-419.

${ }^{5}$ T. Tadaki and C. M. Wayman, Scr. Metall. 14, 911 (1980).

${ }^{6}$ H. C. Lin, S. K. Wu, T. S. Chou, and H. P. Kao, Acta Metall. Mater. 39, 2069 (1991).

${ }^{7}$ Y. F. Zheng, B. M. Huang, J. X. Zhang, and L. C. Zhao, Mater. Sci. Eng., A 279, 25 (2000).

${ }^{8}$ Z. C. Li, X. K. Zhao, H. Zhang, L. Liu, and Y. B. Xu, Mater. Lett. 57, 1086 (2003).

${ }^{9}$ S. R. Zhang and P. G. McCormick, Acta Mater. 48, 3081 (2000).

${ }^{10}$ S. R. Zhang and P. G. McCormick, Acta Mater. 48, 3091 (2000).

${ }^{11}$ J. Ortin and L. Delaey, Int. J. Non-Linear Mech. 37, 1275 (2002).

${ }^{12}$ J. Y. Li, R. C. Rogan, E. Ustundag, and K. Bhattacharya, Nat. Mater. 4, 776 (2005).

${ }^{13}$ S. Rajagopalan, A. L. Little, M. A. M. Bourke, and R. Vaidyanathan, Appl. Phys. Lett. 86, 081901 (2005).

${ }^{14}$ R. Vaidyanathan, M. A. M. Bourke, and D. C. Dunand, J. Appl. Phys. 86, 3020 (1999).

${ }^{15}$ M. A. M. Bourke, R. Vaidyanathan, and D. C. Dunand, Appl. Phys. Lett. 69, 2477 (1996).

${ }^{16}$ S. Miyazaki, T. Imai, Y. Igo, and K. Otsuka, Metall. Trans. A 17, 115 (1986).

${ }^{17}$ R. Vaidyanathan, M. A. M. Bourke, and D. C. Dunand, Mater. Sci. Eng., A 275, 404 (1999).

${ }^{18}$ R. Vaidyanathan, M. A. M. Bourke, and D. C. Dunand, Acta Mater. 47, 3353 (1999).

${ }^{19}$ R. Vaidyanathan, M. A. M. Bourke, and D. C. Dunand, Metall. Mater. Trans. A 32, 777 (2001). 